\title{
O segredo de Brokeback Mountain ou o amor que ainda não diz seu nome
}

Brokeback Mountain.

LEE, Ang (Diretor).

EUA: Focus Features, 2005. 1 DVD (134 $\min$.).

Quando, em fins do século XIX, Lord Alfred Douglas a firmou, em seu poema "Dois Amores", "Eu sou o Amor que não ousa dizer seu nome" não a penas trouxe a o disc urso as relações entre homens, mas o fez no registro do elo amoroso. Assim, to mou como referência a definição de São Paulo sobre a sodomia como o pecado que não devia ser nomeado e a reverteu da esfera das práticas sexuais para a dos sentimentos. Feito similar pode ser creditado ao filme de Ang Lee, cujo roteiro adapta e refina o belo conto de Annie Prouxl, originalmente publicado em 1997.

Ennis Del Mar e Jack Twist são dois jovens pobres que se conhecem ao procurar emprego como pastores de ovelhas durante o verão de 1963 em Wyoming, Estado rural e conservador do Oeste americano. Não são, portanto, cowboys, assim como o filme não é um western, pois a história se passa na segunda metade do século XX. Trata-se de um drama que se insere no recente interesse de Hollywood por personagens que encarnam os losers da sociedade americana.

O trabalho duro, a alimentação ruim e a solidão na montanha aproximam o introvertido Ennis do ma is expansivo Jack, a té que, a pós uma noite de embriaguez, fazem sexo. No dia seguinte, Ennis a firma que aquilo terminava ali. Jack observa: "Isto não interessa a ma is ning uém a lém de nós". Ennis diz que "ain't no queer", ou seja, não era nenhum anormal ou bicha. 0 outro também diz que não. Na mesma noite, Ennis procura Jack na cabana, pede desculpas e, dessa vez, eles fazem amor. Assim, passam do encontro físico para o amoroso e iniciam a relação que marcará suas vidas.

O slogan "O a moré uma força da natureza" soma-se à crua primeira cena de sexo (reproduzida do conto) de forma a essencializar o amor entre os jovens. É como se longe da c iviliza çã o a flora ssem sentimentos ma is na tura is e, portanto, mais puros. Ta is a ssociações fazem parte do vocabulário imagético ocidental ao menos desde Rousseau, masmal encobrem o fato de que, distantes de tudo e de todos, as normas sociais são suspensas e isso é o que permite o envolvimento amoroso dos rapazes.

O idílio na montanha é ameaçado com a descoberta de sua relação pelo contratante que os observa pelo binóculo. Assim, o isolamento e a distância deles no acampamento se revelam ao expectador uma ilusão de proteção sem a qual talvez não tivessem se envolvido. A ordem para que desmontem o acampamento e tragam o rebanho de volta para a planície um mêsantes do combinado é mal recebida por Ennis, cujo mau humor o leva a iniciar uma briga em que ambos saem feridos e com as camisas manchadas de sangue.

Os amigos retornam para a planície. Aparentemente, aquela relação teminaria em meio às sanções socia is. Isso parece corroborado quando, após a contagem das ovelhas, os a migos se despedem sem trocar nem um a perto de mão. Pelo retrovisorde sua caminhonete velha, Jack observa Ennis seguind o pela estrada. O que não vê é a dor que se apodera do caminhante, uma verdadeira reação de corpo e alma que o leva a procurar um canto na estrada pensando que vai vomitar, mas termina por chorar escondido e esmurra a parede diante do sofrimento da separação.

Não é uma experiência comum a todas as pessoas constata rque seus sentimentos mesc lam o desejo amoroso com o medo de ser rejeitado e perseguido. Um amor que não pode ser declarado e tem como lugar o segredo é vivenciado como contradição diante da sociedade. É assim que o filme retoma o tema do a morproibido presente em melodramas, mas o enriquece por confrontar os sentimentos dos prota gonistas não com restriç õ es c irc unstanc ia is, mascom toda a ordem social que os rejeita.

Ennis casa-se com Alma, tem duas filhas e sobrevive em trabalhos brutos. A pobreza e a conformida de a os padrões soc ia is ma rc a m Ennis de maneira tal que é difícil dissoc iar rua cond ição econômica desfavorecida da vida restrita a que se conforma. Jack é mais a mbicioso e em um 
rodeio conhece uma moça texana rica, filha de um comerciante de equipamentosa gríc olas, com a qual se casa e tem um filho.

Quatro anos depois da despedida, Jack envia um cartão a Ennis perguntando se poderia visitá-lo. Ele responde: "Pode a postar que sim". A cena do reencontro é uma das ma is dramáticas do filme, pois os dois não conseguem se contere trocam beijos do lado de fora da casa enquanto Alma os vê pela vidraça. A beleza da paixão incontida se mescla ao susto da esposa ao descobrir o segredo do marido.

Pela segunda vez, o amor dos dois se converte em um segredo aberto ${ }^{1} \mathrm{e}$, dessa forma, o filme leva o expectadora temerpelo futuro dos dois apaixonados que estão mais expostos e vulneráveis do que imaginam. Além disso, nos vemos no dilema entre a cumplicidade com os amantes e a simpatia pela esposa traída. A obrigação social de se relacionar com pessoas do sexo oposto, a heterossexualidade compulsória, enreda todosem suas teias, inclusive as companheiras. ${ }^{2}$

Logo depois do reencontro, Jack propõe que abandonem suas vidas de casados e construam outra juntos em um rancho isolado. Ennis relata que na infância sabia de um casa de homensque, apesarde sériose trabalhadores, eram motivo de piada em sua comunidade. Um dia, seu pai o levou para o vero cadáver de um deles, o qual fora assa ssina do e joga do no canal de irrigação. Segundo Ennis, prova velmente seu pai fizera o serviço. Assim, pondera que dois homens não podem viver juntos e só lhes resta se conformarem a encontros esporádicos na montanha.

Contraditoriamente unidospormeio de uma separação e pelo distanciamento da sociedade, vivem, a o mesmo tempo, seu a more seu segredo. A obrigação social da invisibilida de se expressa nos silêncios que perpassam a história e a enriquecem, pois sã o justa mente os silênc ios que c aracterizam relações entre indivíduos estig ma tiza dos. Nenhum dos p rota g onistas diz eu te amo. 0 que não pode ser dito é convertido em uma troca de olhares a partir de um código de iniciados. A comunic ação por olhares converte o amor do julgamento moral no da cumplicidade estratégica entre os subalternizados. o que os une, assim, é tão partic ularaos do is quanto socia Imente moldado.

Alma separa-se de Ennis e ele se apega ao trabalho duro para cumprir as obrigações com as filhas. Ensaia um romance com uma garçonete, mas se decide pela solidão. Jack, mais passional e financeiramente estável, progressivamente não se conforma com os encontros esporádicos e se envolve com um vizinho. No último enc ontro dos dois, J a ck desfere a frase "Quem me dera saber como te deixar", diante da qual Ennis desmorona e revela que por causa do que sente pelo outro não tinha mais nada, talvez nem mesmo forças para continuar a suportar a quela situação.

Diante de um cartão que retoma com o carimbo "falecido", Ennis liga para a esposa de Jack. O rela to de Lureen sobre a morte do marido em um suposto acid ente com um pneu estoura do é seguido por imagens de um espancamento, o que contra diz sua versã o e mostra a o expecta dor que ele foi assassinado. 0 último desejo dele era o de que suas cinzas fossem espalhadas na montanha Brokebacke porisso ela enviara parte das cinzas para a família, em Lighting Flats, por acharque lá ficava o local.

Ennis segue até o rancho decadente em que vivem os pais de Jack. John Twist é um patriarca decadente cuja fala descreve o fracasso do filho. Nessa cena, descobre-se que Jack nunca escondera Ennis dos seus, mas por fim tentara mudarpara a li com o vizinho texano, decisão que precipitou sua morte.

A comunicação não-verbal entre os personagens alcança seu ápice na troca de olhares entre Ennise a mãe de Jack. Ela o convida para ir sozinho ao quarto do filho delegando a ele a intimidade e confiando-Ihe um último segredo. No quarto austero e pobre, Ennis sente curiosida de pelo a rmário a berto e a o entrarnele percebe que, no fundo, em uma parte escondida, há um cabide com as ca misas sujas de sangue pela briga no último dia de acampamento daquele verão de 1963. Em meio à penumbra e no aperto do armário ele as abraça como se nelas pudesse ainda sentir o amigo. As camisas guardadas revelam a Ennis que Jack também o amara desde o início e sofrera a o se despedirem vinte anos antes.

De volta à sala, Ennis se aproxima da mãe de Jack com as camisas em suas mãos. Eles trocam mais um olhar cordato e ela o ajuda a guardá-las em um saco de papel enquanto escutam J ohn Twist sentenciar que as cinzas do filho serão enterradas no jazigo familiar. A mãe o mira nos olhos e pede para que ele venha visitá los novamente. É como se fizessem um acordo para cumprir o último desejo de Jack.

Historic a mente, as mulheres torna ram-se ma is sensiveis a sina is nã o-verba is, a prenderam a identificar melhor uma emoção não representada verbalmente e decifrar o que está implíc ito em um diálogo. Gays, a o contrário, por 
serem homens que foram criados para a heterossexualidade, costumam compreender melhor o ponto de vista dos dominantes do que o seu. ${ }^{3}$ Nessa cena, Ennis passa poruma inflexão que não existe no conto. Ele terá que usar do mesmo tipo de astúcia da mãe de Jack para subverter o sistema do segredo aberto que moldou sua vida e matou seu amado.

A cena final ta mbém não existe no conto e evidencia a visão política dos roteiristas Diana Ossana e Larry McMurtry com relação às polêmicas contra o casamento gay. A filha de Ennis va i visitá-lo em seu trailer. Está com 19 a nos, a mesma idade que ele tinha quando conheceu Jack. Alma J r. vem notic iar-lhe seu casamento e pedirque ele vá à cerimônia. Ele titubeia porque tinha um rebanho para cuidar, mas aceita o convite. Quando a filha se vai, percebe que ela esquec eu seu suéter. Assim, o dobra e ao abrir o armário para guardá-lo vemos que mantém penduradas na porta as camisas velhas e um postal da montanha Brokeback. É como se mirasse 0 amor perdido e cujas cinzas nem the pertencem - a prova de amor mantida em segredo. Com o olhar turvo diz: "Iack, eu prometo" e fecha o armário. A câmera se fixa na imagem da porta fechada, bem ao lado da janela, enquanto a bela música de Gustavo Santaolalla se eleva.

A história que já era conhecida nos bastidores de Hollywood como o melhor roteiro impossível de se produzir demorou sete a nosa se materializar em um filme de orçamento baixo e que, tudo indicava, seria relegado a um circ uito alternativo. Ao contrário do esperado, a obra tomou-se sucesso de público e de crítica. Nos Estados Unidos, sua repercussã o foi benefic ia da pelo conhecimento geral de que a história se passa na região em que um rapazgay, Martthew Shepard, foi brutalmente assassinado em 1998. Ta mbém é o local de origem de George W. Bush, presidente eleito em meio à controvérsia de acrescentar uma emenda à constituição proibind o o casamento entre pessoas do mesmo sexo.

No Brasil, a recepção se dá quando o casamento gay alcança certa relevância na mídia, mas o decisivo parece ser o fato de que em nossa sociedade é forte a invisibilização de a mores como o de Ennis e Jack. O armário continua a existire o segredo a inda é regra para a imensa maioria das pessoas que amam outras do mesmo sexo, em especial as que vivem em cidades pequenas e médias. Nesse sentido, o filme tem maior alcance por deslocar a problemática de uma classe média cosmopolita, daqueles que podem ser ma is a propria da mente chamados de gays, para pessoas menos favorecidas e ma is expostas às sanções mora is e à violência.

Brokeback Mountain mostra como vivemos em uma sociedade estrutura da no jogo do visível e do invisível, do dito e do silenciado, do plenamente vivido e do que é mantido em segredo. A mesma ilusão de invisibilidade que permite que 0 amor entre Jack e Ennis se realize na montanha os aprisiona na condição do segredo aberto. Nele, a rejeição da relação é dupla: pelos parceiros amorosos que a concebem como questão privada e pelos que sabem e convertem-se em algozes. O contratante expressa sua repulsa porJ ackquando ele retoma em busca de emprego; Alma, a esposa traída, revela seu nojo pela relação do marido em uma conversa enquanto a esposa de Jack termina como a provável mandante de seu assassinato. Todos, sem exceção, são enredados no mesmo mecanismo social que constitui a experiência de vida dos protagonistas. ${ }^{4}$

A estrutura do segredo aberto e o fim de Jack expõem o caráter elusivo da escolha entre viver esc ondido ou sair do armário. Aqueles que vivem seu amor de forma clandestina estão expostos ao perigo e quanto mais o segredo é aberto mais rigor e violência emergem para a manutenção das nomas socia is. Quem sai do a mário coloca outros dentro dele. Alma, sem poder viver ma is o conflito do segredo do marido, pede o divórcio, mas a esposa de Jack vê-se jogada contra a ordem social pela decisão do marido de a deixare reage de forma assassina.

A obrigação social da invisibilida de mantém atual o amor impossível expresso na metáfora c lá ssica do viver no armário. Os roteiristas enfatizam essa experiência nas cenas finais ao foc a rem as camisas sujas de sangue, símbolo dos conflitos da relação. De um a rmário ao outro, o amor é mantido em segredo por vinte anos, o que o filme dramatiza de forma a politizar o privado e fazer da história de amor de Ennis Del Mar e Jack Twist um épico em que um casal marginaliza do revela-se heróic o a té no fracasso. Enquanto no final do conto permanece o conformismo de que se deve agüentaro que não tem jeito, na versão escrita pelos roteiristas Ennis fic a entre o segredo no a rmário e a promessa de não ac eitar as coisas como elas ainda são.

\section{Notas}

${ }^{1}$ Cf. Eve SEDGWICK, 1993, p. 53.

2 Sobre heteronomatividade consulte J oan

SCOT, 1998, e SEDGWICK, 1993. 
3 Pierre BOURDIEU, 1999, p.42-43.

${ }^{4}$ Cf. SC OTT, 1998.

\section{Referências bibliográficas}

BOURDIEU, Pierre. A dominação masculina. Rio de Janeiro: Bertrand Bra sil, 1999.

SCOT, J oan W. "A invisibilida de da experiência". Projeto História, São Paulo, n. 16, p. 297-325, fev. 1998.
SEDGWICK, Eve K. "The Epistemology of the Closet." In: ABELOVE, Henry; BARALE, Michèle Aina, and HALPERIN, Da vid (eds.). The Lesbian and Gay Studies Reader. London/New York: Routledge, 1993. p. 45-61.

Richard Miskolc Universida de Federal de São Carlos, SP

564 Estudos Feministas, Floria nópolis, 14(2): 549-571, maio-agosto/2006 